\title{
Short-Term Synaptic Depression Is Topographically Distributed in the Cochlear Nucleus of the Chicken
}

\author{
Stefan N. Oline and R. Michael Burger \\ Department of Biological Sciences, Lehigh University, Bethlehem, Pennsylvania 18015
}

In the auditory system, sounds are processed in parallel frequency-tuned circuits, beginning in the cochlea. Activity of auditory nerve fibers reflects this frequency-specific topographic pattern, known as tonotopy, and imparts frequency tuning onto their postsynaptic target neurons in the cochlear nucleus. In birds, cochlear nucleus magnocellularis (NM) neurons encode the temporal properties of acoustic stimuli by "locking" discharges to a particular phase of the input signal. Physiological specializations exist in gradients corresponding to the tonotopic axis in NM that reflect the characteristic frequency (CF) of their auditory nerve fiber inputs. One feature of NM neurons that has not been investigated across the tonotopic axis is short-term synaptic plasticity. NM offers a rather homogeneous population of neurons with a distinct topographical distribution of synaptic properties that is ideal for the investigation of specialized synaptic plasticity. Here we demonstrate for the first time that short-term synaptic depression (STD) is expressed topographically, where unitary high CF synapses are more robust with repeated stimulation. Correspondingly, high CF synapses drive spiking more reliably than their low CF counterparts. We show that postsynaptic AMPA receptor desensitization does not contribute to the observed difference in STD. Further, rate of recovery from depression, a presynaptic property, does not differ tonotopically. Rather, we show that another presynaptic feature, readily releasable pool (RRP) size, is tonotopically distributed and inversely correlated with vesicle release probability. Mathematical model results demonstrate that these properties of vesicle dynamics are sufficient to explain the observed tonotopic distribution of STD.

Key words: tonotopy; topographic map; synaptic plasticity; short-term synaptic depression; release probability; readily releasable pool

\section{Introduction}

Short-term synaptic depression (STD) is a fundamental property expressed throughout the nervous system. Mechanisms of STD have been investigated at diverse synapses including the neuromuscular junction (Liley and North, 1953; Elmqvist and Quastel, 1965; Betz, 1970), the squid giant synapse (Kusano and Landau, 1975), the climbing fiber to Purkinje cell synapse (Dittman and Regehr, 1998; Xu-Friedman et al., 2001), and the calyx of Held (Wu and Borst, 1999; Neher and Sakaba, 2001). STD is computationally significant because synaptic efficacy is highly dependent on recent activity. This is particularly important for temporally sensitive neurons like those in the auditory pathway that receive relatively few synaptic inputs, where each input has a large influence on postsynaptic spike probability. We therefore investigated synaptic efficacy in topographically organized auditory synapses.

Sound processing occurs in parallel circuits organized according to the frequency to which neurons are most sensitive. This "tonotopic" organization originates in the cochlea, where audi-

\footnotetext{
Received July 19, 2013; revised Dec. 11, 2013; accepted Dec. 13, 2013.

Author contributions: S.N.O. and R.M.B. designed research; S.N.O. and R.M.B. performed research; S.N.O. analyzed data; S.N.O. and R.M.B. wrote the paper.

This work was supported by NIH/NIDCD Grant DC-008989. We thank Dr. Julie Haas for help with data analysis, Dr. Yong Lu and Dr. Matthew Xu-Friedman for advice, and Dr. William Coleman, Dr. Matthew Fischl, and Jana Nerlich for methods and editorial comments. The authors declare no competing financial interests.

Correspondence should be addressed to Dr. R. Michael Burger, Associate Professor, Department of Biological Sciences, Lehigh University, 111 Research Drive, Bethlehem, PA 18015. E-mail: burger@lehigh.edu.

DOI:10.1523/JNEUROSCI.3073-13.2014

Copyright $\odot 2014$ the authors $\quad 0270-6474 / 14 / 341314-11 \$ 15.00 / 0$
}

tory nerve (nVIII) fibers inherit their tuning from their hair cell inputs. Lower-frequency ( $<2 \mathrm{kHz}) \mathrm{nVIII}$ fibers also encode temporal information by "locking" discharges to a particular stimulus phase (Warchol and Dallos, 1990; Köppl, 1997; Fukui et al., 2006), and precise phase-locking is necessary for binaural computations of sound source location. These nVIII fibers synapse onto nucleus magnocellularis (NM), a division of the cochlear nucleus in birds.

Neurons in NM are arranged along a tonotopic rostro-caudal axis (Rubel and Parks, 1975). Frequency tuning imparts a gradient of temporal constraints at synapses along this axis with respect to phase-locking, in that the stimulus period varies over orders of magnitude. Accordingly, several anatomical and physiological features of NM neurons vary systematically by tonotopic position. For example, high characteristic frequency (CF) neurons $(>2500 \mathrm{~Hz})$ receive only a few large nVIII inputs, whereas low CF neurons $(<500 \mathrm{~Hz})$ receive $8-10$ small inputs (Köppl, 1994; Fukui and Ohmori, 2004). It is unknown how this gradient of unitary synaptic input magnitudes influences processing in NM. Further, the contribution of prominent STD observed in NM has not been investigated with respect to the tonotopic axis (Zhang and Trussell, 1994a; Brenowitz and Trussell, 2001b; Fukui and Ohmori, 2004).

We investigated how unitary inputs along the tonotopy vary in their ability to evoke postsynaptic discharges in NM neurons. We show that, compared with high CF inputs, low CF synapses are less effective at evoking responses in NM neurons in a stimu- 
lus rate-dependent manner. One mechanism that may underlie this observation is STD. We demonstrate that STD is differentially expressed along the tonotopic axis such that high CF synapses exhibit less depression than do low CF inputs to NM. Further, we demonstrate that the mechanisms underlying the gradient of STD arise largely from presynaptic factors, including differences in the number of vesicles available in the readily releasable pool (RRP), and the correlated release probability values at those synapses. Together, these data suggest that short-term plasticity in NM may be tuned according to tonotopic position, primarily through presynaptic vesicle dynamics.

\section{Materials and Methods}

We recorded from 143 cells, using 41 White Leghorn chicks (Gallus gallus domesticus) of either sex, aged E19-P2. Fertilized eggs were obtained from a commercial poultry supplier (Moyer's Chicks) and raised at Lehigh University's central animal facility. All procedures were approved by the Lehigh University Institutional Animal Care and Use Committee and were performed in compliance with the Public Health Service Policy on Human Care and Use of Laboratory Animals.

In vitro brain slice preparation. Before surgery, embryos were brought to room temperature, while post-hatch subjects were anesthetized with isoflurane (MINRAD). Chicks were rapidly decapitated and the brainstem containing auditory nuclei was removed, blocked, and submerged in oxygenated artificial CSF (aCSF; containing, in mM: $130 \mathrm{NaCl}, 3 \mathrm{KCl}, 10$ glucose, $1.25 \mathrm{NaH}_{2} \mathrm{PO}_{4}, 26 \mathrm{NaHCO}_{3}, 3 \mathrm{CaCl}_{2}$, and $1 \mathrm{MgCl}_{2}$ ) at $22^{\circ} \mathrm{C}$. The brainstem was placed rostral surface down on the stage of a vibrating microtome (Microm International) to collect $200 \mu \mathrm{m}$ coronal sections containing the NM. Sections were maintained in topographic order in an incubation chamber of continuously oxygenated aCSF and incubated at $37^{\circ} \mathrm{C}$ for $\sim 1 \mathrm{~h}$, and then maintained at room temperature until used for recording. The tonotopic position of NM slices was estimated according to position along the rostro-caudal dimension (Rubel and Parks, 1975; Fukui and Ohmori, 2004). Using the topographic position scheme of the Ohmori group, NM neurons were assigned to one of three topographically ordered CF subsections (Fukui and Ohmori, 2004). Low CF neurons were defined as those within the first (most caudal) slice that contained NM and the lateral half of the second slice. High CF neurons were defined as those within the last slice containing NM and the medial half of the second-to-last slice. All other neurons were defined as middle CF.

Recording arrangement. Brainstem slices were placed in a custom recording chamber on a retractable chamber shuttle system (Siskiyou), and neurons were visualized with a Nikon FN-1 Physiostation microscope using infrared differential interference contrast optics. Video images were captured using a CCD camera (Hamamatsu) coupled to a video monitor. The recording chamber was continuously superfused with $\mathrm{aCSF}$ at a rate of $1-2 \mathrm{ml} / \mathrm{min}$. Measurements of $\left[\mathrm{Ca}^{2+}\right]$ in chick CSF are in the range of 2.5-2.8 mM (Maki et al., 1990), and many previous studies in chick NM have used aCSF with $3 \mathrm{~mm}\left[\mathrm{Ca}^{2+}\right]$ (Raman and Trussell, 1992; Trussell et al., 1993; Zhang and Trussell, 1994a,b; Otis et al., 1996; Brenowitz and Trussell, 2001a,b; Lu and Trussell, 2007). To allow for direct comparison, we performed all experiments in $3 \mathrm{~mm}\left[\mathrm{Ca}^{2+}\right] \mathrm{aCSF}$. An inline feedback temperature controller and heated stage (Warner Instruments) were used to maintain chamber temperature at $35 \pm 1^{\circ} \mathrm{C}$, which was verified daily with a calibration thermistor. Principal NM neurons were identified based on their characteristic round morphology.

Patch pipettes were pulled from thick-walled borosilicate glass capillary tubes (WPI) to a resistance of 3-7 M $\Omega$ using a two-stage puller (Narishige) and back-filled. We used a potassium-based solution for current-clamp experiments (containing, in mM: $145 \mathrm{~K}$-gluconate, $5 \mathrm{KCl}$, $1 \mathrm{MgCl}_{2}, 10$ HEPES, and 5 EGTA, $\mathrm{pH}$ adjusted to 7.2 with $\mathrm{KOH}$ ), and a cesium-based solution for voltage-clamp experiments (containing, in mM: $125 \mathrm{CsMeSO}_{3}, 15 \mathrm{CsCl}, 1 \mathrm{MgCl}_{2}, 10$ HEPES, 5 EGTA, $\mathrm{pH}$ adjusted to 7.2 with $\mathrm{CsOH}$ ). For voltage-clamp experiments, QX-314 (5 mM) was added to the internal solution to prevent antidromic action potentials. Only cells with a resting membrane potential negative to $-50 \mathrm{mV}$ were used. For voltage-clamp experiments, membrane potential was clamped at $-60 \mathrm{mV}$ using an Axon Multiclamp 700B amplifier, and series resistance was com- pensated at $60-70 \%$. Junction potentials were calculated and not corrected ( $15.3 \mathrm{mV}$ in current clamp, and $13.9 \mathrm{mV}$ in voltage clamp).

The signal was digitized with a Digidata 1440 data acquisition board and recorded using Clampex software (Molecular Devices). EPSCs were evoked by $50 \mu$ s stimulus pulses with a stimulus isolation unit (A.M.P.I.) through either a bipolar tungsten electrode or an aCSF-filled monopolar glass electrode. To isolate AMPA-mediated EPSCs, $20 \mu \mathrm{M}$ SR-95531 hydrobromide (SR), $500 \mathrm{~nm}$ strychnine hydrochloride (SN), and $50 \mu \mathrm{M}$ D-(-)-2-amino-5-phosphonopentanoic acid (AP5) were added to aCSF. Cyclothiazide (CTZ) was added at $40 \mu \mathrm{m}$ from a stock solution in DMSO to evaluate the role of AMPA receptor desensitization, and an equivalent concentration of DMSO was added to the control solution for these experiments. To ensure that CTZ did not affect presynaptic release, in a separate experiment, we measured the number of spontaneous EPSCs (sEPSCs) during $30 \mathrm{~s}$ recording epochs. We observed no significant change in number of sEPSCs following application of CTZ (987.40 \pm 786.66 sEPSCs in control, $810.20 \pm 678.39$ in CTZ; Student's paired $t$ test, $p=0.644, n=5$ ).

EPSCs were evoked by electrical stimulation of single nVIII inputs. We positioned the stimulating electrode over the tissue surface with a micromanipulator (Siskiyou), in a dorsolateral position proximal to the cell of interest. Unitary evoked EPSCs were isolated using a minimum stimulation protocol (Dobrunz and Stevens, 1997). EPSCs were considered unitary provided that EPSC amplitude was independent of stimulus amplitude (range 5-90 V), EPSC latency and kinetics were consistent, and EPSCs responded in an all-or-none manner so that a reduction in the stimulus amplitude led to a complete loss of the EPSC. Synaptic inputs that did not meet these criteria were discarded. Large EPSCs had a tendency to not decay completely before the onset of subsequent EPSCs, which then summated. The amplitude of these EPSCs was therefore measured from the inflection point of the evoked response riding on the previous EPSC, rather than from zero. Tonic current was measured as the residual current excluding the transient component of the EPSC.

We used $30 \mathrm{~s}$ recording epochs to estimate sEPSC quantal size. To ensure that sEPSCs were representative of single quanta and not multivesicular release, we observed them before and after tetrodotoxin (TTX) application in five cells. There was no difference in the mean sEPSC amplitude in the presence or absence of TTX $(-127.3 \pm 35.1 \mathrm{pA}$ in control, $-105.1 \pm 21.8 \mathrm{pA}$ in TTX, $n=5, p=0.12$, paired-samples $t$ test). Since sEPSC amplitudes did not change, and the evoked EPSC amplitude was typically an order of magnitude greater than sEPSC amplitude, we interpreted the mean sEPSC amplitude of each cell to be an estimate of quantal size. All drugs were acquired from Sigma, except for TTX from Alomone Labs and SR and AP5 from Tocris Bioscience.

Mathematical model of STD. To simulate depression of EPSCs, we modified a previously developed mathematical model that incorporated both vesicle depletion and receptor desensitization (Brenowitz and Trussell, 2001a). Inputs to the model were based on empirical data whenever possible, including release probability $\left(P_{\mathrm{R}}\right)$, total number of release sites $\left(N_{0}\right)$, and quantal size $(q)$ in pA. To equate $N_{0}$ with RRP size, we assumed univesicular release for each release site. Parameters were calculated immediately before and immediately after synaptic release, and included the number of release sites occupied with a readily releasable vesicle $\left(N_{\mathrm{i}}\right)$, and the fraction of receptors that were in a nondesensitized state $\left(\beta_{\mathrm{i}}\right)$. Initial, rested values were $N_{\mathrm{i}}=N_{0}$ and $\beta_{\mathrm{i}}=1$, and the number of vesicles released per pulse, or quantal content $\left(m_{\mathrm{i}}\right)$, was calculated as the product of $N_{\mathrm{i}}$ and $P_{\mathrm{R}}$. The resultant peak EPSC amplitude $\left(I_{\mathrm{i}}\right)$ was calculated as follows: $I_{\mathrm{i}}=m_{\mathrm{i}}^{*} q^{*} \beta_{\mathrm{i}}$.

An intermediate step between pulses calculated values for $N_{\mathrm{i}}$ and $\beta_{\mathrm{i}}$ immediately following the preceding pulse. Accordingly, the number of occupied release sites immediately after release $\left(N_{\mathrm{i} \text { post }}\right)$ was described as: $N_{\mathrm{i} \text { post }}=N_{\mathrm{i}}{ }^{*}\left(1-P_{\mathrm{R}}\right)$, and the fraction of nondesensitized receptors was described as: $\beta_{\mathrm{i} \text { post }}=1-A^{\star}\left(m_{\mathrm{i}} / N_{0}\right)^{B}$, where $A$ and $B$ are scaling factors for the magnitude of receptor desensitization.

Finally, recovery of depleted release sites and desensitized receptors were calculated using time constants $\tau_{\text {rec }}$ and $\tau_{\beta}$, respectively. The number of occupied release sites at the onset of the next pulse were therefore described as follows, dependent on the interstimulus interval (int): $N_{\mathrm{i}+1}=N_{\mathrm{i} \text { post }}+\left(P_{\mathrm{R}}{ }^{\star} N_{0}\right){ }^{*}\left[1-\exp \left(-\mathrm{int} / \tau_{\text {rec }}\right)\right]$. Similarly, the fraction 
of nondesensitized receptors available for the next pulse were calculated as: $\beta_{\mathrm{i}+1}=\beta_{\mathrm{i} \text { post }}+$ $\left(1-\beta_{\text {i post }}\right) *\left[1-\exp \left(-\mathrm{int} / \tau_{\beta}\right)\right]$. These new values for $N$ and $\beta$ were then used as initial values for the next pulse. We best approximated observed depression kinetics of nVIII-NM synapses by setting $\tau_{\text {rec }}$ to $20 \mathrm{~ms}, \tau_{\beta}$ to $800 \mathrm{~ms}, A$ to 2.5 , and $B$ to 3 .

Statistics. All data in Results are expressed as percentage of control \pm SD. Error bars in figures represent SE. ANOVA and Tukey's post hoc test were used for comparisons among the three populations. Significance was corrected using Greenhouse-Geisser for two-way mixed repeated-measures ANOVAs. Curve fits and plotting were performed in MATLAB (MathWorks) and Clampfit (Molecular Devices), and comparisons were calculated in SPSS Statistics (IBM). Curves were fitted with a double exponential function, $y=A_{1}{ }^{*} \exp \left(-t / \tau_{\text {fast }}\right)+$ $A_{2}{ }^{\star} \exp \left(-t / \tau_{\text {slow }}\right)+C$, where $A_{1}$ and $A_{2}$ are weighting factors, $\tau_{\text {fast }}$ and $\tau_{\text {slow }}$ are the fast and slow time constants, respectively, and $C$ was a constant included in recovery fits that was constrained to 1 . The reported, weighted tau values $\left(\tau_{\mathrm{w}}\right)$ were calculated as the following: $\tau_{\mathrm{w}}=\left[\left(A_{1}\right.\right.$ $\left.\left.{ }^{*} \tau_{\text {fast }}\right)+\left(A_{2}{ }^{*} \tau_{\text {slow }}\right)\right] /\left(A_{1}+A_{2}\right)$.

\section{Results}

Spike entrainment to unitary synaptic input differs across the tonotopic axis in NM

Neurons in low CF regions of NM have a higher input resistance and a longer axon initial segment than those in high CF regions and are, thus, more excitable (Fukui and Ohmori, 2004; Kuba and Ohmori, 2009). However, unitary nVIII inputs to low CF cells are known to be $\sim 10$-fold smaller than those to high CF cells (Fukui and Ohmori, 2004). To investigate how this tonotopic variation in inputs to NM leads to differences in spike entrainment to repetitive stimuli, we examined postsynaptic responses to unitary input stimulation across the tonotopy of NM using whole-cell current clamp.

Neurons were selected from both high $(n=14)$ and low $(n=$ 12) CF regions. Postsynaptic discharges could be evoked by a unitary single-pulse input in all synapses, with the exception of two low CF synapses that were excluded from further analysis. $\mathrm{GABA}_{\mathrm{A}}$ and glycine receptors were blocked with antagonists SR $(20 \mu \mathrm{M})$ and $\mathrm{SN}(500 \mathrm{nM})$, respectively. We then presented 15 pulse stimulus trains at 50,100, and $200 \mathrm{~Hz}$. Figure $1 A$ shows 10 representative traces for both high and low CF NM cells following $100 \mathrm{~Hz}$ stimulation. Over the course of the stimulus train, spike probability typically decreased, especially for low CF synapses. Temporal jitter generally increased with pulse number for both high and low CF synapses. This trend was especially pronounced for low CF synapses; however, the larger increase in temporal jitter of spike time for these synapses was not statistically different from that for the high CF synapses $(p=0.37$ ). Responses to the first and 15th pulse are illustrated on expanded timescales in Figure $1 B$, where the differences in spike probability are most evident. Indeed, we found that low CF synapses failed more often at every stimulus rate. This feature is illustrated in Figure $1 C$ for data recorded at $50 \mathrm{~Hz}($ i), $100 \mathrm{~Hz}$ (ii), and $200 \mathrm{~Hz}$ (iii), and was statistically significant in each condition $(2 \times 15$ mixed repeated-measures ANOVA, $F_{(2.33,39.65)}=3.996, p=0.021$ at
$50 \mathrm{~Hz}, F_{(3.34,60.16)}=8.493, p=0.000048$ at $100 \mathrm{~Hz}$, and $F_{(2.93,58.56)}=3.741, p=0.016$ at $\left.200 \mathrm{~Hz}\right)$.

These data confirm the conclusion from previous studies that while unitary nVIII inputs to NM neurons are usually capable of evoking a response, their efficacy is highly dependent on stimulus rate and duration (Zhang and Trussell, 1994b; Brenowitz and Trussell, 2001b). However, this property is more pronounced at low CF synapses compared with their high CF counterparts. This observation suggests that in addition to the several known tonotopically distributed physiological features in this structure, it is possible that a stimulus-dependent synaptic property such as STD may contribute to the response pattern that we observed. We therefore evaluated STD at single nVIII-NM excitatory synapses across the tonotopic axis in NM.

\section{Synaptic depression of unitary synaptic inputs differs across the tonotopic axis in NM}

NM neurons from frequency-specific regions were voltage clamped at $-60 \mathrm{mV}$ during stimulation of single presynaptic nVIII fibers to record pharmacologically isolated unitary EPSCs. In a manner similar to that of the previous experiment, we stimulated nVIII fibers with 15 pulse trains at 50,100, and $200 \mathrm{~Hz}$ (Fig. 2). Figure $2 A$ shows representative averaged traces from individual high and low CF cells, which are presented together and normalized to the amplitude of EPSC ${ }_{1}$ in Figure $2 B$ (arrows indicate amplitude of 15 th pulse). As expected, synaptic responses exhibited prominent STD, and initial EPSC amplitude was larger in high CF cells than in low CF cells (Zhang and Trussell, 1994a; Fukui and Ohmori, 2004). The magnitude of STD, however, varied systematically between tonotopic positions. For low CF cells, STD was significantly larger compared with high CF inputs (Fig. 2C, data fitted with double exponential functions; see Materials and Methods). As a metric of STD, a depression index was calculated as the difference between 1 and the mean of the 
A

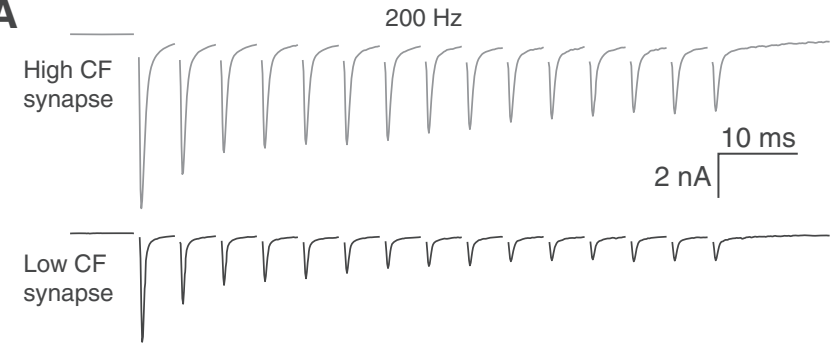

C $\quad$ i $50 \mathrm{~Hz}$

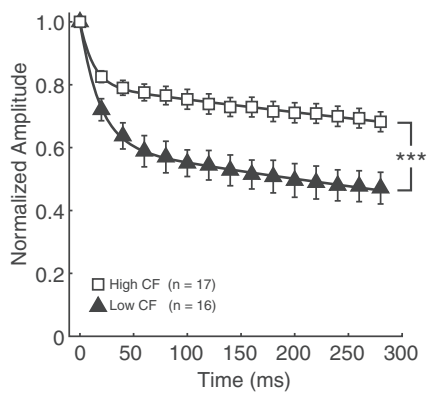

ii $100 \mathrm{~Hz}$

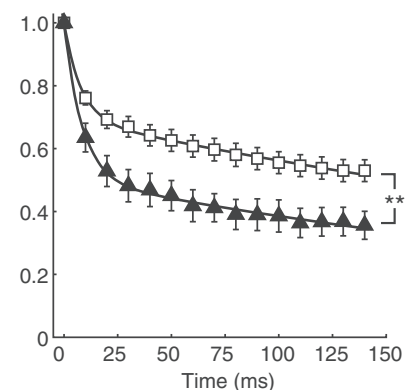

B

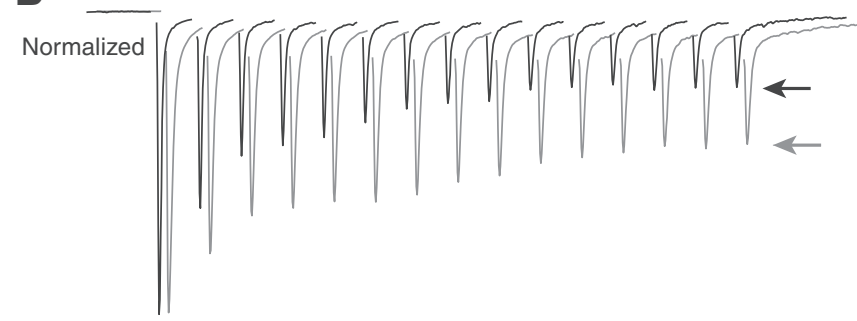

iii $200 \mathrm{~Hz}$

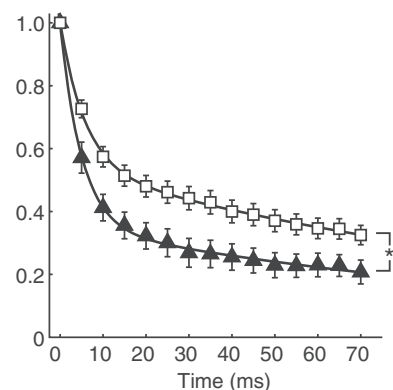

D

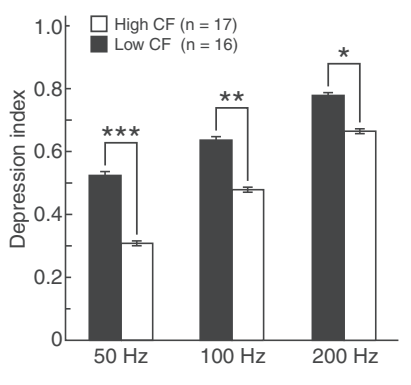

Figure 2. Synaptic depression of unitary synaptic inputs differs across the tonotopic axis in NM. $A$, Comparison of recordings in voltage clamp from two representative synapses in NM, 15-pulse stimulation at $100 \mathrm{~Hz}$. High CF cell, gray trace; low CF cell, black trace. B, Overlay of traces in A, normalized to first EPSC (arrow indicates final amplitude, traces offset on time axis for clarity). C, Population data of normalized responses at $50 \mathrm{~Hz}$ (i), $100 \mathrm{~Hz}$ (ii), and $200 \mathrm{~Hz}$ (iii) for high (squares) and low (triangles) CF synapses. Curves shown are fitted to means with a double exponential function (see Materials and Methods). Time constants ( $\tau_{\mathrm{w}}$ ) of fits for high and low (F synapses, respectively, were $1449.4 \mathrm{~ms}$ and $772.8 \mathrm{~ms}$ for $50 \mathrm{~Hz}, 329.7 \mathrm{~ms}$ and $204.1 \mathrm{~ms}$ for $100 \mathrm{~Hz}$, and $77.6 \mathrm{~ms}$ and $49.5 \mathrm{~ms}$ for $200 \mathrm{~Hz}$. D, Depression index is different at every stimulus rate for high (white bars) and low (black bars) CF synapses (Student's $\mathrm{t}$ test, $n=17$ for high and 16 for low CF, $0.308 \pm 0.130$ and $0.524 \pm 0.197,{ }^{* * *} p=0.000763$ at $50 \mathrm{~Hz} ; 0.479 \pm 0.138$ and $0.636 \pm .179,{ }^{* *} p=0.00792$ at $100 \mathrm{~Hz}$; and $0.664 \pm 0.132$ and $0.778 \pm 0.145,{ }^{*} p=0.0251$ at $200 \mathrm{~Hz}$ ).

final 3 normalized EPSC values in the train, so that the depression index ranged from a minimum of 0 , indicating no depression, to a maximum of 1 , indicating complete depression. The depression index was significantly lower at high CF synapses for all stimulus rates measured (Fig. $2 D$, Student's $t$ test, $n=17$, white bars for high CF and $n=16$, black bars for low CF, $0.308 \pm 0.130$ and $0.524 \pm 0.197, p=0.000763$ at $50 \mathrm{~Hz} ; 0.479 \pm 0.138$ and $0.636 \pm$ $.179, p=0.00792$ at $100 \mathrm{~Hz}$; and $0.664 \pm 0.132$ and $0.778 \pm$ $0.145, p=0.0251$ at $200 \mathrm{~Hz}$ ). We next investigated several candidate mechanisms which may contribute to the robust tonotopically distributed STD observed here.

\section{Postsynaptic contributions to STD are not tonotopically arranged}

STD has been shown in previous studies to depend on both presynaptic and postsynaptic mechanisms. If presynaptic plasticity were invariant across the tonotopy, postsynaptic properties such as receptor desensitization could lead to the apparent difference in STD. AMPA receptor desensitization at NM synapses is known to be dependent on the magnitude of the glutamate signal in the synapse (Raman and Trussell, 1992). Therefore, large EPSCs at high CF synapses may desensitize postsynaptic receptors to a greater extent than the smaller EPSCs observed at low CF synapses. It is then possible that postsynaptic receptor desensitization varies along the tonotopic axis and contributes to the tonotopic distribution of STD. To test this hypothesis, we first evaluated unitary EPSC size along the tonotopy and its relationship to STD. In a second experiment, we blocked AMPA receptor desensitization with CTZ and evaluated its contribution to STD.

Figure $3 A i$ shows the distribution of initial EPSC amplitude for high (white bars) and low (black bars) CF neurons. Consistent with previous reports, markedly smaller synaptic inputs were observed for very low CF synapses. Indeed, the rested EPSC ampli- tude distribution for low CF neurons had a mean initial EPSC amplitude of $-3.71 \pm 2.51 \mathrm{nA}$, while the mean for high CF neurons was significantly larger at $-8.30 \pm 3.37 \mathrm{nA}$ ( $t$ test, $n=28$ and 32, respectively; $p=0.0000001$ ). Figure 3 Aii shows initial EPSC amplitude plotted against the depression index for the 50 $\mathrm{Hz}$ protocol in Figure 2C. EPSC amplitude and depression index were not correlated for either high $(r=0.267, p=0.14)$ or low $(r=-0.220, p=0.26)$ CF cells. Pooling the data across the tonotopic axis showed that peak amplitude was also not significantly correlated with the depression index $(r=-0.238, p=$ 0.067). These data suggest that EPSC amplitude effects alone are not likely to underlie the observed differences in STD.

Although EPSC amplitude at rested synapses is not strongly correlated with the depression index, receptor desensitization may vary across the tonotopy and contribute to the distribution of STD. Since NM synapses have been shown to exhibit prominent AMPA receptor desensitization, which influences depression (Trussell et al., 1993; Zhang and Trussell, 1994a; Otis et al., 1996; Brenowitz and Trussell, 2001a), we examined this possibility by using a desensitization antagonist, CTZ. If desensitization contributes to stronger depression in low CF synapses, then one would predict that CTZ would relieve a greater amount of desensitization in low CF cells.

Application of $40 \mu \mathrm{M}$ CTZ increased the decay time of EPSCs as expected (Fig. 3B). When we stimulated synapses with 15 pulse trains in both control aCSF and in the presence of CTZ (Fig. 3C), CTZ treatment caused EPSCs to sum with the decaying tail of a previous current, especially at high stimulus rates. This resulted in a residual, "tonic," component of the EPSC. Therefore, postsynaptic currents were measured in two ways. First, transient EPSC amplitude was measured from its onset inflection point (Fig. 3C, EPSC). Second, tonic current was measured as the current remaining after the transient components of individual EPSCs were subtracted (see Materials and Methods). 
A i

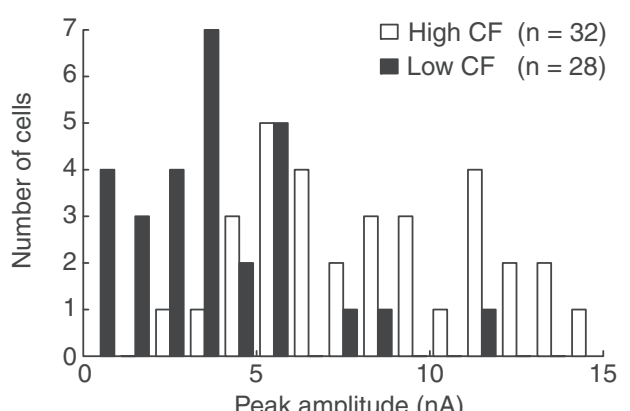

ii

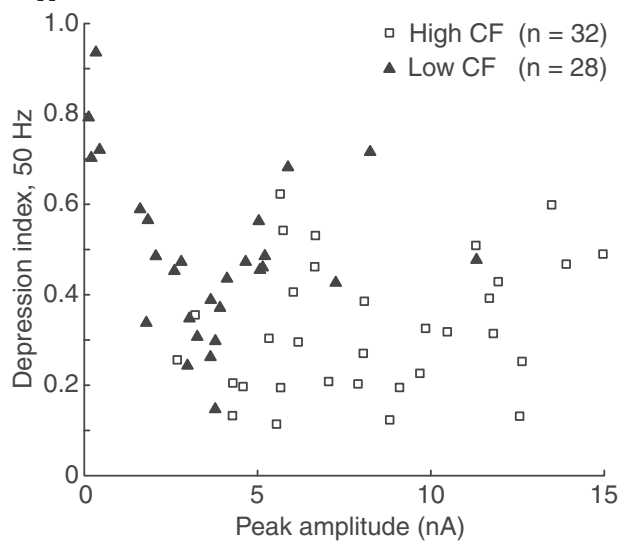

B

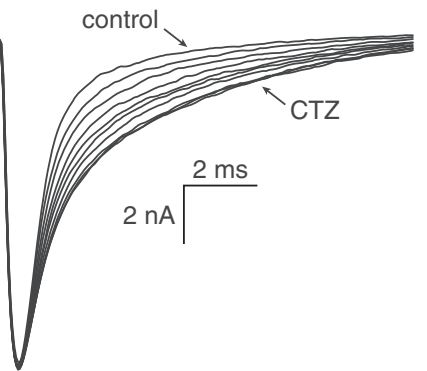

D Transient current

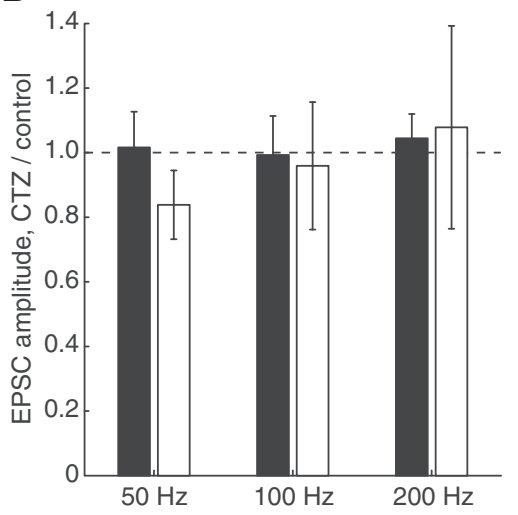

C

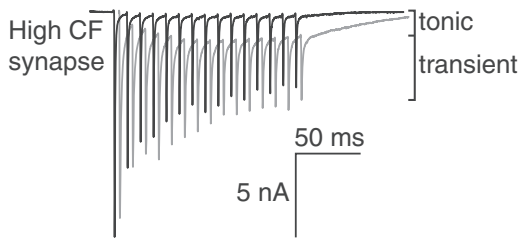

Low CF
synapse
E Tonic current

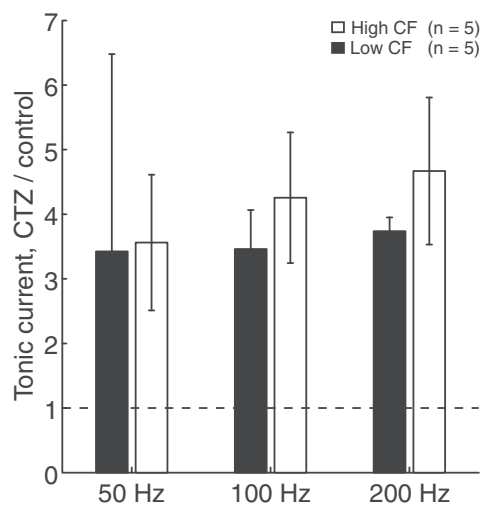

Figure 3. Postsynaptic contributions to STD are not tonotopically arranged. $A$, Distribution of initial peak EPSC amplitudes for high and low CF synapses. As observed in previous publications, this histogram (Ai) demonstrates that peak EPSC amplitude is larger for high CF cells (white bars) than for low CF cells (black bars). Bin centers are slightly offset for clarity. Below (Aii), peak EPSC amplitude is plotted with depression index, which is not correlated. $\boldsymbol{B}$, EPSCs during application of CTZ. Recordings were taken every $20 \mathrm{~s}$ until the increase in decay time saturated ( $3-5$ min). $\boldsymbol{C}$, Representative traces from high and low CF cells in control (black) and $40 \mu \mathrm{M}$ CTZ (gray). Tonic and transient current is highlighted, and traces are offset in the time axis for clarity. $\mathbf{D}$, Change in transient EPSC amplitude (mean, final 3 pulses) after application of CTZ, as a fraction of control amplitude. Dashed line represents unity. Both low (black bars) and high (white bars) CF data are shown. $\boldsymbol{E}$, Change in tonic EPSC amplitude (mean, final 3 pulses) after application of CTZ, as a fraction of control amplitude.

We investigated relief from desensitization by comparing the mean of the final three EPSC amplitudes recorded in control aCSF and in CTZ (Fig. 3D, dashed line represents no change). We found that transient EPSC amplitudes were not different between conditions in either population (Table 1). Additionally, we observed that tonic current increased approximately 4 -fold in both populations during application of CTZ at high stimulus rates, which did influence overall depression (Fig. 3E; Table 1). Importantly, however, the degree of relief from depression was not different between low and high CF populations. Since we observed similar current increases in both low and high CF synapses when relieving AMPA receptor desensitization, it is unlikely that postsynaptic receptor desensitization contributes to the observed stronger STD at low CF synapses. Rather, these findings suggest that presynaptic mechanisms are more likely to contribute to this phenomenon.

Presynaptic mechanisms contribute to STD differences along the tonotopic axis

Presynaptic features of NM synapses could underlie STD via regulation of vesicle release or availability. To first assess whether presynaptic factors could contribute to the difference in STD observed along the tonotopy, we calculated the coefficient of variation (CV) for the EPSCs in Figure 2, as shown for a low CF neuron (Fig. 4A). CV has previously been used to infer changes in quantal content, a presynaptic feature (Martin, 1966; Zhang and Trussell, 1994a; Kuba et al., 2002). EPSCs with a low quantal content exhibit large, stepwise variation, because individual

\section{Table 1. Receptor desensitization does not influence tonotopic distribution of STD}

\begin{tabular}{clll}
\hline & Control \pm SD $(\mathrm{pA})$ & $\mathrm{CTZ} \pm \mathrm{SD}(\mathrm{pA})$ & $p$ value \\
\hline $\begin{array}{c}\text { Transient EPSC amplitudes } \\
\text { High CF }\end{array}$ & & & \\
$50 \mathrm{~Hz}$ & $-6326.96 \pm 1093.95$ & $-5188.79 \pm 1176.66$ & 0.15 \\
$100 \mathrm{~Hz}$ & $-3446.47 \pm 817.71$ & $-3232.48 \pm 1609.97$ & 0.80 \\
$200 \mathrm{~Hz}$ & $-1378.55 \pm 611.34$ & $-1492.35 \pm 1412.65$ & 0.87 \\
Low CF & & & \\
$50 \mathrm{~Hz}$ & $-2626.82 \pm 349.36$ & $-2695.73 \pm 831.45$ & 0.87 \\
$100 \mathrm{~Hz}$ & $-2087.74 \pm 477.55$ & $-2096.99 \pm 747.37$ & 0.98 \\
$200 \mathrm{~Hz}$ & $-1266.59 \pm 481.97$ & $-1275.14 \pm 399.72$ & 0.98 \\
Tonic EPSC amplitudes & & & \\
High CF & & & \\
$50 \mathrm{~Hz}$ & $-363.80 \pm 280.20$ & $-1074.10 \pm 1067.87$ & 0.19 \\
$100 \mathrm{~Hz}$ & $-551.73 \pm 247.88$ & $-2178.13 \pm 1519.34$ & 0.05 \\
$200 \mathrm{~Hz}$ & $-714.23 \pm 233.55$ & $-3181.49 \pm 1566.97$ & 0.01 \\
Low CF & & & \\
$50 \mathrm{~Hz}$ & $-23.00 \pm 20.99$ & $-63.23 \pm 105.14$ & 0.43 \\
$100 \mathrm{~Hz}$ & $-80.47 \pm 75.82$ & $-263.29 \pm 242.54$ & 0.15 \\
$200 \mathrm{~Hz}$ & $-197.13 \pm 137.32$ & $-730.60 \pm 486.96$ & 0.05 \\
\hline
\end{tabular}

Transient (top) and tonic (bottom) EPSC amplitudes in control or CTZ conditions at 50, 100, or $200 \mathrm{~Hz}$ stimulation rates. Student's $t$ test $p$ values are shown in right column for each comparison. Statistics for tonotopic position comparisons are shown in Results.

quanta contribute a large percentage of the EPSC amplitude. Conversely, EPSCs with a large quantal content exhibit less variation, as each vesicle represents only a small component of the EPSC. Changes in CV with repeated stimuli indicate a change in presynaptic vesicle release characteristics. This property is illus- 

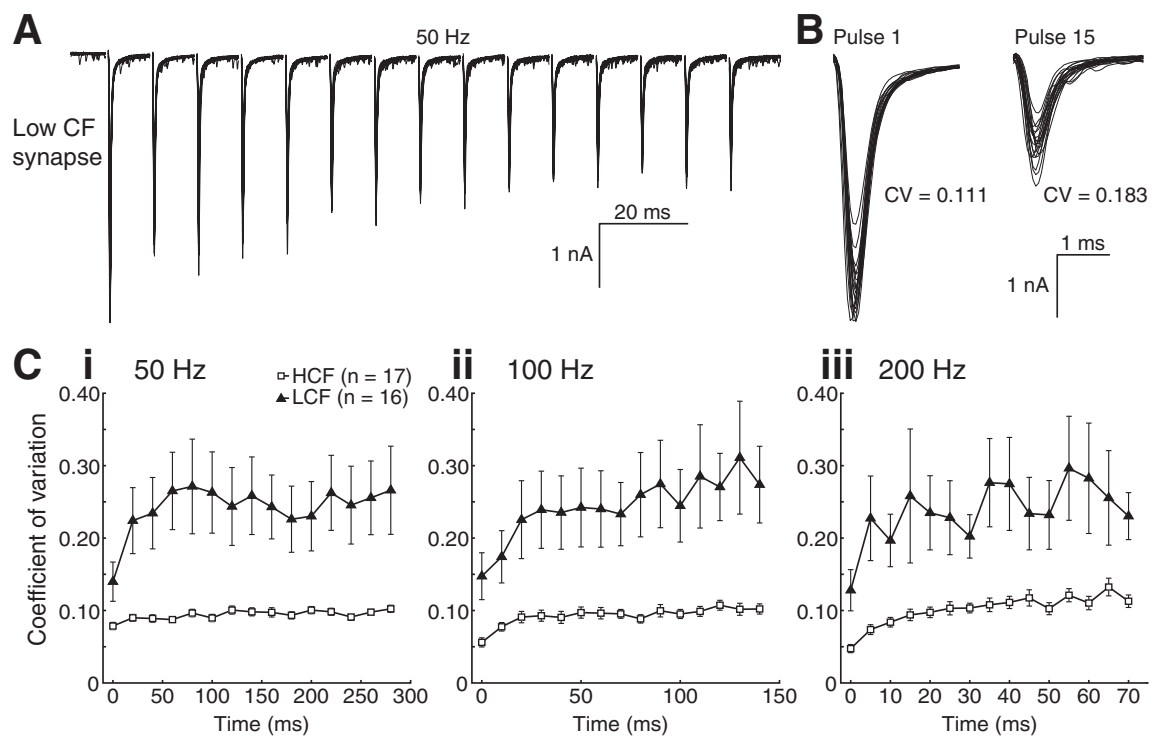

Figure 4. Presynaptic mechanisms contribute to STD differences along the tonotopic axis. $\boldsymbol{A}$, Ten representative traces of a recording of a low CF cell. B, Expanded time base for pulses 1 and 15, with calculated CV. C, Calculated CV of populations for 50 (i), 100 (ii), and 200 (iii) Hz. High CF cells had a lower rested CV than their low CF counterparts ( $n=17$ and 16 for high and low CF, means $=0.079 \pm 0.021$ and $0.140 \pm 0.179, p=0.029$, Student's $t$ test).

trated in Figure $4 B$, which shows pulses 1 and 15 on an expanded time base with calculated CVs. High CF cells had a lower rested $\mathrm{CV}$ than their low CF counterparts $(n=17$ and 16 for high and low CF, means $=0.079 \pm 0.021$ and $0.140 \pm 0.179, p=0.029$, Student's $t$ test), suggesting that EPSCs in high CF neurons had a larger quantal content. Additionally, CV increased over the duration of the stimulus for both populations in all but the low $\mathrm{CF}$, $200 \mathrm{~Hz}$ data (Fig. 4C), which suggests a decrease in EPSC quantal content in both populations during STD.

These results indicate an activity-dependent reduction in EPSC quantal content. Presynaptic features relevant to vesicle trafficking such as differences in rates of vesicle replenishment, release probability, and the number of vesicles available for release may underlie the observed differences in synaptic depression. We performed experiments to test each of these possible mechanisms of STD.

\section{Recovery of EPSC amplitude following STD is not tonotopically distributed}

The rate of EPSC recovery after STD is known to affect depression kinetics (O'Donovan and Rinzel, 1997; Dittman and Regehr, 1998). Following STD, depleted vesicles are replenished from a recycling pool (Elmqvist and Quastel, 1965; Südhof, 2000; Rizzoli and Betz, 2005). Since the time interval between stimuli is brief during high stimulus rate trains, the fast recovery time constant $\left(\tau_{\text {r-fast }}\right)$ has the greatest influence on STD kinetics. We predicted that if recovery rate contributes to the tonotopic distribution of STD, recovery kinetics would be faster for high CF synapses.

To examine whether the rate of EPSC recovery contributes to the observed difference in STD, we observed recovery following a conditioning train of 20 pulses at $50 \mathrm{~Hz}$ (Fig. $5 \mathrm{~A}$ ). A test pulse was applied at various time points following the conditioning train, from 25 to $3200 \mathrm{~ms}$. The response was then compared with the initial EPSC amplitude to evaluate recovery from depression (Fig. 5B). Consistent with data shown in Figure 2, low CF synapses depressed to a greater extent than high CF synapses (Student's $t$ test, $n=10$ and 8 for high and low CF, depression index $=0.668 \pm$ 0.177 and $0.478 \pm 0.123, p=0.021$ ). EPSC recovery of the population means in all but one cell was well described by standard double exponential fits for both low and high CF populations (Fig. $5 C)$. We used a weighted tau $\left(\tau_{\text {r-w }}\right)$ to provide a direct comparison between curve fits with differing weights for $\tau_{\mathrm{r}-}$ fast and $\tau_{\mathrm{r} \text {-slow }}$, representing the time in milliseconds required to recover from $\sim 63 \%$ of EPSC depression (see Materials and Methods). Although low CF synapses had a greater depression index, curve fits to mean data were remarkably $\operatorname{similar}\left(\tau_{\mathrm{r}-\mathrm{w}}=1.171\right.$ and $1.185 \mathrm{~s}$, for high and low CF, respectively). Correspondingly, $\tau_{\mathrm{r}-\mathrm{w}}$ values calculated from individual recovery functions were not statistically different between high and low CF populations $\left(\tau_{\mathrm{r}-\mathrm{w}}=1.339 \pm\right.$ $1.094 \mathrm{~s}, n=10$, and $1.451 \pm 0.926 \mathrm{~s}, n=$ 8 , for high and low CF, respectively; Student's $t$ test, $p=0.82$ ). Together, these results indicate that vesicle recovery following depletion is not responsible for our observed difference in STD between high and low CF synapses. We next examined vesicle pool sizes as a potential mechanism.

\section{Readily releasable pool size varies systematically along the tonotopic axis}

Presynaptic vesicles that are available for immediate release upon the arrival of an action potential are known as "readily releasable vesicles," and reside in the empirically defined RRP. Depletion of vesicles from the RRP is a major contributor to STD (Liley and North, 1953; von Gersdorff and Matthews, 1997; Wang and Kaczmarek, 1998; Schneggenburger et al., 2002; Zucker and Regehr, 2002; Foster and Regehr, 2004; Taruno et al., 2012). The fraction of vesicles within the RRP that are released following a single presynaptic action potential is known as release probability, which also influences the rate of depression at these synapses (Brenowitz and Trussell, 2001a). Since both RRP size and release probability contribute to STD properties, we investigated whether either or both varied tonotopically and thus could contribute to our observed differences in STD.

To estimate the quantal content of an EPSC (the number of vesicles released in response to a single-action potential), we used the following equation, $\mathrm{EPSC}_{\text {amplitude }}=N^{\star} p^{\star} q$, where evoked EPSC amplitude is described as the product of three components: the quantity of readily releasable vesicles in the RRP $(N)$, the probability of release of an individual readily releasable vesicle in response to a presynaptic action potential $(p)$, and the quantal size of a readily releasable vesicle $(q)$. Quantal size was estimated using sEPSCs (Fig. 6A), which are thought to draw from the same vesicle pool as those released during evoked activity (Groemer and Klingauf, 2007). We recorded 30 s of spontaneous activity to estimate mean sEPSC amplitude, which was smaller for low, compared with high, $\mathrm{CF}$ synapses, whereas middle CF synapses were not different from either group $(-73.9 \pm 23.9 \mathrm{pA},-81.4 \pm$ $31.3 \mathrm{pA}$, and $-89.2 \pm 24.2 \mathrm{pA}$ for low, middle, and high CF synapses, respectively; one-way ANOVA, $p=0.095$, Student's $t$ test, $p=0.022$ ). 
We estimated RRP size and release probability using long depression trains (Fig. 6B) in low, middle, and high CF synapses (Schneggenburger et al., 1999). This method has been applied successfully in NM and many other synapses (Brenowitz and Trussell, 2001b; Kirischuk et al., 2005; Stevens and Williams, 2007; Kawasaki and Ordway, 2009; Pan and Zucker, 2009; Babai et al., 2010; Lou et al., 2012; Thanawala and Regehr, 2013). To isolate vesicles that were initially in the RRP from those replenished during stimulation, we applied a 40 pulse, $100 \mathrm{~Hz}$ stimulus to the presynaptic nVIII fiber to bring synaptic responses to a steady state. Current exceeding steady state was interpreted as originating from vesicles within the RRP, and divided by quantal size to estimate the quantity of readily releasable vesicles. To segregate this current from steady state, a cumulative amplitude plot was constructed for each neuron, and a line was fit to the final 10 pulses where the steady state creates a linear slope that is extrapolated back to the $y$ intercept (Fig. $6 C$, population data plotted to illustrate variance).

The current value at the $y$-intercept provides the estimate of quanta in the RRP (Fig. 6C, arrows). Vesicle release probability was then calculated as the fraction of vesicles from the RRP released by the first pulse.

RRP size was significantly greater in middle $(n=16)$ and high $(n=32)$ CF neurons than in low $(n=24)$ CF neurons (Fig. $6 D$, one-way between-subjects ANOVA, $F_{(2,69)}=10.997, p=$ 0.000072 , post hoc $p=0.00031$ and 0.00055 , respectively). Release probability trended toward lower values with tonotopic position (Fig. 6E) but was not statistically different between tonotopic groups (one-way between-subjects ANOVA, $F_{(2,69)}=0.141, p=$ $0.87)$. We then examined the relationship between each individual cell's estimated RRP size and release probability. As shown in Figure $6 F$, release probability was significantly inversely correlated with RRP size on a synapse-by-synapse basis $(r=-0.34$, $p=0.0038$ ). Both RRP size and release probability are factors controlling vesicle availability and, therefore, are expected to have a direct impact on STD. The distribution bias of either high RRP size or low release probability toward high CF synapses may therefore underlie the observed tonotopic distribution of STD.

\section{Observed release probability distribution is sufficient to generate tonotopic variation in STD}

RRP size and release probability are presynaptic factors that should predominantly influence the early phase of depression as the RRP is being depleted. We therefore examined early and late phase kinetics of depression during 40 pulse stimuli with respect to tonotopic position. As with the 15 pulse stimuli observed in Figure 2, depression for these synapses was well represented by double exponential decay functions with both fast and slow components (see Materials and Methods). The values for tau weighted $\left(\tau_{\mathrm{w}}\right)$, which describes the overall kinetics of depression, were significantly smaller for low $\mathrm{CF}$ synapses than for either middle or high CF (Fig. 7A, one-way between-subjects ANOVA, $F_{(2,63)}=6.640, p=0.0024$, post hoc $p=$ 0.014 and 0.0035 , respectively), confirming that low CF synapses depress faster than high CF synapses. When the underlying kinetic components were analyzed separately, the slow component $\left(\tau_{\text {slow }}\right)$ was not different between groups (Fig. $7 B$, one-way betweensubjects ANOVA, $\left.F_{(2,63)}=0.901, p=0.41\right)$. However, $\tau_{\text {fast }}$ values were significantly smaller for low compared with high CF synapses (Fig. $7 C$, Student's $t$ test, $p=0.010$ ), consistent with rapid depletion of their smaller RRPs. Together, the tonotopic distribution of RRP size and depression kinetics suggest that depletion of the RRP directly contributes to the observed tonotopic variation in STD.

Our data suggest two possible presynaptic mechanisms responsible for the observed difference in depression: RRP size and release probability. To examine how each of these mechanisms could contribute to STD, we used a mathematical model that incorporated both vesicle depletion and receptor desensitization. We were first interested in the explanatory power of RRP size for synaptic depression. To test this, we simulated the 40 pulse, $100 \mathrm{~Hz}$ tetanus protocol used above. Grand population mean values were used to set release probability (0.2817) and quantal size $(-82.38 \mathrm{pA})$. Additionally, input parameters were adjusted so that a curve fitted to the model's normalized EPSC amplitude had decay values representative of the broad range of empirical $\tau_{\text {fast }}, \tau_{\text {slow }}$, and depression index values as release probability or RRP size varied. The $\tau_{\text {fast }}$ grand mean of empirical data was $12.2 \pm 5.91 \mathrm{~ms}$, while that for $\tau_{\text {slow }}$ was $918 \pm 578$ $\mathrm{ms}$, and depression index was $0.659 \pm 0.172$. Using the grand population mean for release probability and RRP size, output from the mathematical model was well fit by a double exponential curve, which had a $\tau_{\text {fast }}$ of $13.0 \mathrm{~ms}$, a $\tau_{\text {slow }}$ of $766 \mathrm{~ms}$, and a depression index of 0.612 . We then set the number of initially occupied release sites $\left(N_{0}\right)$ to six representative values chosen from the population data (marked $A-F$ in Fig. 6F; 50, 150, 250, 350, 450, and 550 release sites). Since manipulation of $N_{0}$ scaled EPSC amplitude, but not relative vesicle replenishment or receptor desensitization, we saw no effect on depression kinetics (Fig. 7D).

We then asked if changes to release probability could lead to differences in depression kinetics similar to those we observed across the tonotopic axis. Release probabilities varied greatly across the 

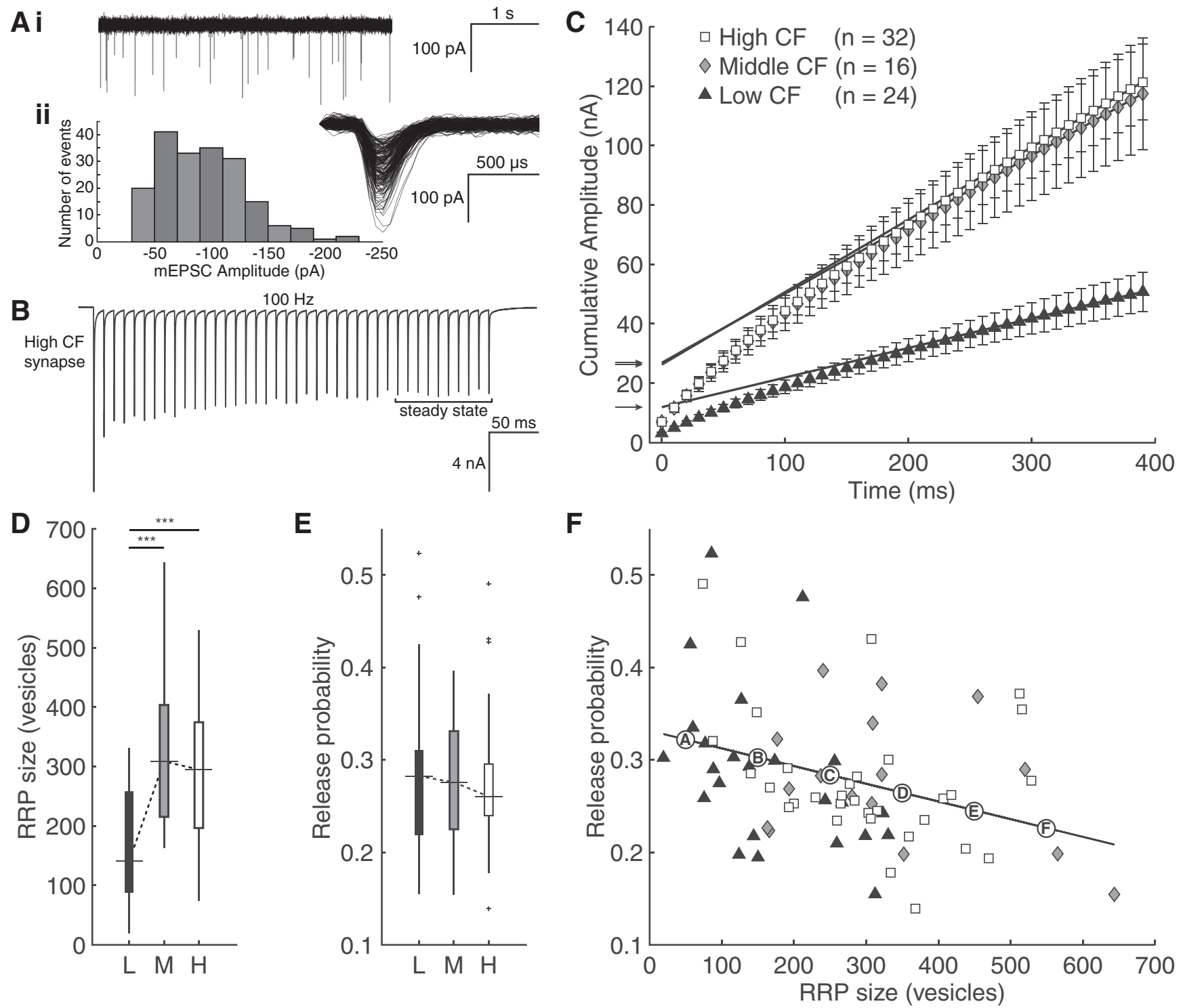

Figure 6. Readily releasable pool size varies systematically along the tonotopic axis. A, Representative sEPSC trace ( $4 \mathrm{~s} ; \boldsymbol{A \boldsymbol { i }})$, and distribution of sEPSC amplitudes (Aii) recorded from a representative high (F neuron over a 30 s epoch (inset, aligned sEPSCS). $\boldsymbol{B}$, EPSCs evoked in the same neuron by a 40 -pulse, $100 \mathrm{~Hz}$ protocol shows depression to a steady state, measured as the final 10 pulses (highlighted). C, Cumulative amplitude plots of population averages for low (triangles, $n=24$ ), medium (diamonds, $n=16$ ), and high (squares, $n=32$ ) CF groups. Linear fits to the final 10 pulse responses are extrapolated back to the $y$-intercept. Intercepts (arrows) indicate estimate of current from readily releasable vesicles. D, RRP size of low (black box), medium (gray box), and high (white box) CF synapses. Low CF synapses have a significantly smaller RRP size than both middle and high CF synapses (one-way between-subjects ANOVA, $F_{(2,69)}=10.997, p=0.000072, p 0 s t$ $h o c^{* * *} p=0.00031$ and ${ }^{* * *} p=0.00055$, respectively). $\boldsymbol{E}$, Release probability of low (black box), medium (gray box), and high (white box) CF synapses trended downward but was not statistically different (one-way between-subjects ANOVA, $\left.F_{(2,69)}=0.141, p=0.87\right)$. $\boldsymbol{F}$, Scatter plot showing significant trend of inverse correlation between RRP size and release probability $(r=-0.34, p=$ 0.0038). Points $A-F$ mark values used in the mathematical model.

population, so we used six $P_{\mathrm{R}}$ values representing the range of values predicted by the fitted line in Figure $6 D$ and marked with circles $A-F$. $N_{0}$ was held constant at the empirically derived grand mean of 260.76 release sites. Shown in Figure $7 E$, variation of $P_{\mathrm{R}}$ lead to a systematic shift in depression kinetics. The smallest $P_{\mathrm{R}}$ (Fig. $7 E$, line $F, 0.226$ ) corresponded to the portion of the fitted line with the highest RRP size, and exhibited slow depression kinetics characteristic of high CF synapses. In contrast, the largest $P_{\mathrm{R}}$ (Fig. 7E, line $A$, 0.322 ) represented the portion of the fitted line with the smallest RRP size, and exhibited fast depression characteristic of low CF synapses. Together, these data suggest that the observed range of $P_{\mathrm{R}}$ values is sufficient to generate the range of depression kinetics observed across the tonotopy.

\section{Discussion}

In this report, we show for the first time, to our knowledge, shortterm synaptic plasticity at a central synapse that is distributed topographically. Specifically, we demonstrate that STD at the nVIII-NM synapse varies systematically across the tonotopic axis. This feature does not depend on postsynaptic receptor desensitization or on the rate of vesicle replacement. Rather, the data suggest that the mechanism underlying the gradient of STD in NM is variation in release probability. Although RRP size varied topographically, with RRPs in high and middle CF terminals containing approximately twice as many vesicles as low CF terminals, mathematical modeling did not show a relationship between occupied vesicle release sites and de- 
pression kinetics. These data indicate that presynaptic vesicle dynamics, reflected in both postsynaptic action potential entrainment and depression of EPSCs, are likely to be specialized for computational function, in a manner similar to that of several other known topographically distributed morphological and electrophysiological properties in NM. This distribution of STD in NM should have significant computational implications for sound localization specifically, and temporal processing in general.

In the auditory system, tonotopy has driven the expression of several physiological characteristics along this principal axis. For example, NM membrane properties vary such that high CF neurons preferentially express low voltageactivated potassium channels, and have a more hyperpolarized resting potential and fewer voltage-activated sodium channels at the action potential initiation site (Fukui and Ohmori, 2004; Kuba and Ohmori, 2009). The morphology of nVIII inputs to NM is distributed such that high CF inputs terminate in end bulb-like terminals that cover at least $25 \%$ of NM cell circumference; middle CF inputs show a mix of end bulbs and bouton-like structures, whereas low CF inputs show no end bulb-like terminals (Parks, 1981; Jhaveri and Morest, 1982; Carr and Boudreau, 1991; Köppl, 1994; Fukui and Ohmori, 2004). EPSC properties distribute along this gradient in kind; high CF EPSCs have been reported to be an order of magnitude larger, with a less variable evoked EPSC amplitude than their low CF counterparts (Fukui and Ohmori, 2004), a finding confirmed in this study. Depression at these synapses is well described (Zhang and Trussell, 1994a; Brenowitz and Trussell, 2001b), and our findings that both entrainment and STD are tonotopic underscore the likely computational significance of STD at this synapse.

Mechanisms of tonotopically distributed STD are presynaptic One mechanism of synaptic plasticity examined in our study was recovery rate from depression, which is indicative of replenishment of depleted vesicles within the RRP from vesicles in the recycling pool (Wang and Kaczmarek, 1998). Following a $50 \mathrm{~Hz}$ conditioning train, where low CF synapses depressed more than their high CF counterparts, we observed that EPSCs recovered to rested amplitude with similar time constants. Therefore, replenishment of depleted vesicles within the RRP is not likely to be a contributing factor to the observed difference in STD.

We next asked whether vesicle depletion contributed to the observed tonotopic difference in depression; specifically, whether RRP size or release probability was distributed tonotopically. Although we observed only a tonotopic trend in release probability, it was significantly inversely correlated with the tonotopic increase in RRP size. These differences may be due to the gradient of synaptic morphology, from predominantly boutons for low CF to almost exclusively end bulbs of high CF nVIII inputs. Since the density of release sites for vesicles tends to scale uniformly with
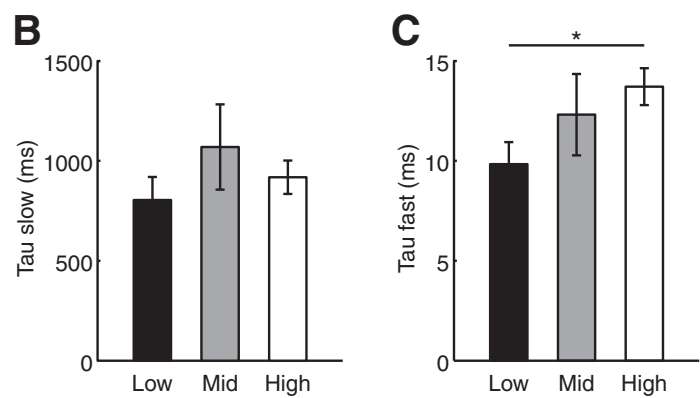

E Variable $P_{\mathrm{R}}$ model

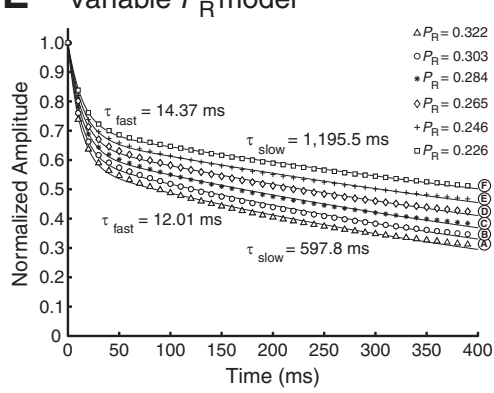

$* N=250$

$\diamond N_{\mathrm{i}}=350$

$+N_{\mathrm{i}}=450$ $\triangle N_{\mathrm{i}}=550$

Figure 7. Observed release probability distribution is sufficient to generate tonotopic variation in STD. $A, \tau_{\mathrm{w}}$ of synaptic 作

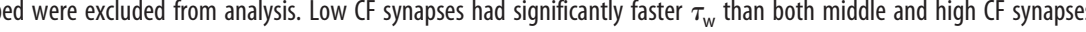

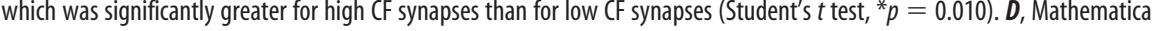
the points on the fitted line in Figure $6 F$, while release probability is held constant at the observed population mean (0.2817). $\boldsymbol{E}$, Mathematical model with release probability varied in 6 conditions $(A-F)$ according to the points on the fitted line in Figure $6 F$, while RRP is held constant at the observed population mean (260.76 vesicles).

surface area (Dondzillo et al., 2010), and the number of synaptic vesicles increases linearly with synapse volume (Pierce and Mendell, 1993; Murthy et al., 2001; Welzel et al., 2011), the larger end bulb-like synapses of high CF inputs likely support a larger RRP. We then found that depression kinetics were dependent on tonotopic position; specifically, we found that $\tau_{\text {fast }}$ of depression was greater in high CF synapses (Fig. $7 \mathrm{C}$ ). The mathematical model showed that the variation in RRP size alone could not explain the depression measures. In contrast, the correlated differences in release probability were sufficient to replicate empirical differences in STD in the model. Together, these data suggest that the distribution of release probability within NM is a primary driver of tonotopic representation of STD.

\section{Functional implications of tonotopically distributed STD}

The systematic variation of STD observed here is likely to have significant functional consequences. Overall, synapses that are resistant to STD tend to have a linear input-output function, whereas synapses that exhibit significant depression preferentially encode the stimulus onset (Tsodyks and Markram, 1997). In bushy cells of the anteroventral cochlear nucleus, mammalian analogs of NM neurons, STD reduces the efficacy of poorly timed inputs relative to well timed inputs, thus improving temporal precision (Yang and Xu-Friedman, 2009). In NL, the target of NM neurons, STD functions as a gain control mechanism by reducing EPSC amplitude with increases in input rate, which may adaptively increase the input synchrony required to initiate spiking at higher stimulus intensities to maintain constant temporal selectivity (Kuba et al., 2002; Cook et al., 2003). Indeed, our observations of entrain- 
ment show similar properties in NM. Further, temporal jitter of spikes in response to single evoked EPSCs is known to be greater in low CF synapses (Fukui and Ohmori, 2004). We observed that in addition to this property, temporal jitter increased with pulse number.

Excitatory currents from rested synapses in NM have been shown to be $\sim 30$-fold threshold current, yet quickly depress below threshold when stimulated at high rates (Zhang and Trussell, 1994a,b). The resistance of high CF synapses to STD may contribute to their ability to initiate postsynaptic spiking during prolonged stimulus trains. However, recent studies at functionally similar synapses have shown that conditioning a synapse with in vivo-like spontaneous stimulus trains constrains the range of STD relative to the first response with a persistent level of depression, while not affecting the rate of recovery (Hermann et al., 2007). The mean spontaneous firing rates of nVIII inputs to NM neurons have been reported in the range of $20-86 \mathrm{~Hz}$ (Manley et al., 1991; Salvi et al., 1992; Saunders et al., 2002; Fukui et al., 2006), suggesting that nVIII inputs are likely to be chronically depressed. If so, the input-output function of NM neurons may be highly dependent on the spontaneous rate of each of its nVIII inputs.

The tonotopically distributed STD that we observe in NM is likely to also have functional consequences for phase-locking. Since stimulus periodicity varies from tens of milliseconds for low CF neurons to 0.5 millisecond or less for neurons representing high-frequency stimuli (Warchol and Dallos, 1990; Köppl, 1997), NM neurons may use different computational strategies to integrate nVIII inputs at different positions along the tonotopic axis. Previous studies have demonstrated that for NM neurons, a larger number of synaptic inputs leads to stronger phase-locking (Kuba and Ohmori, 2009). Low CF neurons, with their higher number of inputs, may integrate several inputs per stimulus cycle to improve phase locking. As in NL, STD may act to increase phase-locking by narrowing the coincidence window required for inputs to cause an action potential. In contrast, the low number of inputs to high CF neurons suggests that integration of several inputs may not be possible. Rather, high CF neurons in NM may be disrupted by spontaneous or poorly timed input, because they lie at a tonotopic position where stimulus frequency far exceeds the spontaneous or driven firing frequency. In this way, high CF synapses may benefit from resistance to STD by ensuring that a chronically depressed input is still capable of driving a response in the absence of coincident multiple inputs. Finally, postsynaptic features such as NM spike threshold are affected on time scales similar to those of STD. Subthreshold input can cause NM neurons to become refractory for a short time, in part due to $\mathrm{Na}^{+}$channel accommodation (Howard and Rubel, 2010). The resistance of high CF synapses to depression also may maintain suprathreshold input to prevent depressed inputs from driving the postsynaptic cell to a refractory state.

In summary, we demonstrate that entrainment of NM neurons, when driven by unitary inputs, is dependent on tonotopic position. We found topographically distributed STD in a central synapse, due primarily to differences in presynaptic properties. Finally, while we show a gradient of RRP size in which high CF RRPs have nearly twice the quantal content observed for low CF synapses, the range of observed release probabilities is more likely to mechanistically influence depression kinetics. It remains unknown exactly how the tonotopic gradient of STD influences the output of NM neurons, or how this feature interacts with other tonotopically distributed features. We predict that synaptic plasticity of nVIII inputs is matched to the membrane properties of their NM targets. This may function to maintain suprathreshold EPSCs in high CF neurons while enabling summation to enhance phase-locking in low CF neurons.

\section{References}

Babai N, Bartoletti TM, Thoreson WB (2010) Calcium regulates vesicle replenishment at the cone ribbon synapse. J Neurosci 30:15866-15877. CrossRef Medline

Betz WJ (1970) Depression of transmitter release at the neuromuscular junction of the frog. J Physiol 206:629-644. Medline

Brenowitz S, Trussell LO (2001a) Minimizing synaptic depression by control of release probability. J Neurosci 21:1857-1867. Medline

Brenowitz S, Trussell LO (2001b) Maturation of synaptic transmission at end-bulb synapses of the cochlear nucleus. J Neurosci 21:9487-9498. Medline

Carr CE, Boudreau RE (1991) Central projections of auditory nerve fibers in the barn owl. J Comp Neurol 314:306-318. CrossRef Medline

Cook DL, Schwindt PC, Grande LA, Spain WJ (2003) Synaptic depression in the localization of sound. Nature 421:66-70. CrossRef Medline

Dittman JS, Regehr WG (1998) Calcium dependence and recovery kinetics of presynaptic depression at the climbing fiber to Purkinje cell synapse. J Neurosci 18:6147-6162. Medline

Dobrunz LE, Stevens CF (1997) Heterogeneity of release probability, facilitation, and depletion at central synapses. Neuron 18:995-1008. CrossRef Medline

Dondzillo A, Sätzler K, Horstmann H, Altrock WD, Gundelfinger ED, Kuner T (2010) Targeted three-dimensional immunohistochemistry reveals localization of presynaptic proteins Bassoon and Piccolo in the rat calyx of Held before and after the onset of hearing. J Comp Neurol 518:1008 1029. CrossRef Medline

Elmqvist D, Quastel DM (1965) A quantitative study of end-plate potentials in isolated human muscle. J Physiol 178:505-529. Medline

Foster KA, Regehr WG (2004) Variance-mean analysis in the presence of a rapid antagonist indicates vesicle depletion underlies depression at the climbing fiber synapse. Neuron 43:119-131. CrossRef Medline

Fukui I, Ohmori H (2004) Tonotopic gradients of membrane and synaptic properties for neurons of the chicken nucleus magnocellularis. J Neurosci 24:7514-7523. CrossRef Medline

Fukui I, Sato T, Ohmori H (2006) Improvement of phase information at low sound frequency in nucleus magnocellularis of the chicken. J Neurophysiol 96:633-641. CrossRef Medline

Groemer TW, Klingauf J (2007) Synaptic vesicles recycling spontaneously and during activity belong to the same vesicle pool. Nat Neurosci 10:145147. CrossRef Medline

Hermann J, Pecka M, von Gersdorff H, Grothe B, Klug A (2007) Synaptic transmission at the calyx of Held under in vivo like activity levels. J Neurophysiol 98:807-820. CrossRef Medline

Howard MA, Rubel EW (2010) Dynamic spike thresholds during synaptic integration preserve and enhance temporal response properties in the avian cochlear nucleus. J Neurosci 30:12063-12074. CrossRef Medline

Jhaveri S, Morest DK (1982) Sequential alterations of neuronal architecture in nucleus magnocellularis of the developing chicken: a Golgi study. Neuroscience 7:837-853. CrossRef Medline

Kawasaki F, Ordway RW (2009) Molecular mechanisms determining conserved properties of short-term synaptic depression revealed in NSF and SNAP-25 conditional mutants. Proc Natl Acad Sci U S A 106:1465814663. CrossRef Medline

Kirischuk S, Jüttner R, Grantyn R (2005) Time-matched pre- and postsynaptic changes of GABAergic synaptic transmission in the developing mouse superior colliculus. J Physiol 563:795-807. CrossRef Medline

Köppl C (1994) Auditory nerve terminals in the cochlear nucleus magnocellularis: differences between low and high frequencies. J Comp Neurol 339:438-446. CrossRef Medline

Köppl C (1997) Phase locking to high frequencies in the auditory nerve and cochlear nucleus magnocellularis of the barn owl, Tyto alba. J Neurosci 17:3312-3321. Medline

Kuba H, Ohmori H (2009) Roles of axonal sodium channels in precise auditory time coding at nucleus magnocellularis of the chick. J Physiol 587: 87-100. CrossRef Medline

Kuba H, Koyano K, Ohmori H (2002) Synaptic depression improves coincidence detection in the nucleus laminaris in brainstem slices of the chick embryo. Eur J Neurosci 15:984-990. CrossRef Medline 
Kusano K, Landau EM (1975) Depression and recovery of transmission at the squid giant synapse. J Physiol 245:13-32. Medline

Liley AW, North KAK (1953) An electrical investigation of effects of repetitive stimulation on mammalian neuromuscular junction. J Neurophysiol 16:509-527. Medline

Lou X, Fan F, Messa M, Raimondi A, Wu Y, Looger LL, Ferguson SM, De Camilli P (2012) Reduced release probability prevents vesicle depletion and transmission failure at dynamin mutant synapses. Proc Natl Acad Sci U S A 109:E515-E523. CrossRef Medline

Lu T, Trussell LO (2007) Development and elimination of endbulb synapses in the chick cochlear nucleus. J Neurosci 27:808-817. CrossRef Medline

Maki AA, Beck MM, Gleaves EW, DeShazer JA, Eskridge KM (1990) CSF ion composition and manipulation during thermoregulation in an avian species, Gallus domesticus. Comp Biochem Physiol A Comp Physiol 96:135140. Medline

Manley GA, Kaiser A, Brix J, Gleich O (1991) Activity patterns of primary auditory-nerve fibres in chickens: development of fundamental properties. Hear Res 57:1-15. CrossRef Medline

Martin AR (1966) Quantal nature of synaptic transmission. Physiol Rev 46:51-66.

Murthy VN, Schikorski T, Stevens CF, Zhu Y (2001) Inactivity produces increases in neurotransmitter release and synapse size. Neuron 32:673682. CrossRef Medline

Neher E, Sakaba T (2001) Combining deconvolution and noise analysis for the estimation of transmitter release rates at the calyx of Held. J Neurosci 21:444-461. Medline

O’Donovan MJ, Rinzel J (1997) Synaptic depression: a dynamic regulator of synaptic communication with varied functional roles. Trends Neurosci 20:431-433. CrossRef Medline

Otis T, Zhang S, Trussell LO (1996) Direct measurement of AMPA receptor desensitization induced by glutamatergic synaptic transmission. J Neurosci 16:7496-7504. Medline

Pan B, Zucker RS (2009) A general model of synaptic transmission and short-term plasticity. Neuron 62:539-554. CrossRef Medline

Parks TN (1981) Morphology of axosomatic endings in an avian cochlear nucleus: nucleus magnocellularis of the chicken. J Comp Neurol 203:425440. CrossRef Medline

Pierce JP, Mendell LM (1993) Quantitative ultrastructure of Ia boutons in the ventral horn: scaling and positional relationships. J Neurosci 13: 4748-4763. Medline

Raman IM, Trussell LO (1992) The kinetics of the response to glutamate and kainate in neurons of the avian cochlear nucleus. Neuron 9:173-186. CrossRef Medline

Rizzoli SO, Betz WJ (2005) Synaptic vesicle pools. Nat Rev Neurosci 6:5769. CrossRef Medline

Rubel EW, Parks TN (1975) Organization and development of brain stem auditory nuclei of the chicken: tonotopic organization of n. magnocellularis and n. laminaris. J Comp Neurol 164:411-433. CrossRef Medline

Salvi RJ, Saunders SS, Powers NL, Boettcher FA (1992) Discharge patterns of cochlear ganglion neurons in the chicken. J Comp Physiol A Neuroethol Sens Neural Behav Physiol 170:227-241.

Saunders JC, Ventetuolo CE, Plontke SKR, Weiss BA (2002) Coding of sound intensity in the chick cochlear nerve. J Neurophysiol 88:28872898. CrossRef Medline
Schneggenburger R, Meyer AC, Neher E (1999) Released fraction and total size of a pool of immediately available transmitter quanta at a calyx synapse. Neuron 23:399-409. CrossRef Medline

Schneggenburger R, Sakaba T, Neher E (2002) Vesicle pools and short-term synaptic depression: lessons from a large synapse. Trends Neurosci 25: 206-212. CrossRef Medline

Stevens CF, Williams JH (2007) Discharge of the readily releasable pool with action potentials at hippocampal synapses. J Neurophysiol 98:3221-3229. CrossRef Medline

Südhof TC (2000) The synaptic vesicle cycle revisited. Neuron 28:317-320. CrossRef Medline

Taruno A, Ohmori H, Kuba $\mathrm{H}$ (2012) Inhibition of presynaptic $\mathrm{Na}(+)$ / $\mathrm{K}(+)$-ATPase reduces readily releasable pool size at the avian end-bulb of Held synapse. Neurosci Res 72:117-128. CrossRef Medline

Thanawala MS, Regehr WG (2013) Presynaptic calcium influx controls neurotransmitter release in part by regulating the effective size of the readily releasable pool. J Neurosci 33:4625-4633. CrossRef Medline

Trussell LO, Zhang S, Raman IM (1993) Desensitization of AMPA receptors upon multiquantal neurotransmitter release. Neuron 10:1185-1196. CrossRef Medline

Tsodyks MV, Markram H (1997) The neural code between neocortical pyramidal neurons depends on neurotransmitter release probability. Proc Natl Acad Sci U S A 94:719-723. CrossRef Medline

von Gersdorff H, Matthews G (1997) Depletion and replenishment of vesicle pools at a ribbon-type synaptic terminal. J Neurosci 17:1919-1927. Medline

Wang LY, Kaczmarek LK (1998) High-frequency firing helps replenish the readily releasable pool of synaptic vesicles. Nature 394:384-388. CrossRef Medline

Warchol ME, Dallos P (1990) Neural coding in the chick cochlear nucleus. J Comp Physiol A Neuroethol Sens Neural Behav Physiol 166:721-734.

Welzel O, Henkel AW, Stroebel AM, Jung J, Tischbirek CH, Ebert K, Kornhuber J, Rizzoli SO, Groemer TW (2011) Systematic heterogeneity of fractional vesicle pool sizes and release rates of hippocampal synapses. Biophys J 100:593-601. CrossRef Medline

Wu LG, Borst JG (1999) The reduced release probability of releasable vesicles during recovery from short-term synaptic depression. Neuron 23 : 821-832. CrossRef Medline

Xu-Friedman MA, Harris KM, Regehr WG (2001) Three-dimensional comparison of ultrastructural characteristics at depressing and facilitating synapses onto cerebellar Purkinje cells. J Neurosci 21:6666-6672. Medline

Yang H, Xu-Friedman MA (2009) Impact of synaptic depression on spike timing at the endbulb of Held. J Neurophysiol 102:1699-1710. CrossRef Medline

Zhang S, Trussell LO (1994a) Voltage clamp analysis of excitatory synaptic transmission in the avian nucleus magnocellularis. J Physiol 480:123-136. Medline

Zhang S, Trussell LO (1994b) A characterization of excitatory postsynaptic potentials in the avian nucleus magnocellularis. J Neurophysiol 72:705718. Medline

Zucker RS, Regehr WG (2002) Short-term synaptic plasticity. Annu Rev Physiol 64:355-405. CrossRef Medline 